\title{
Endoscopic submucosal dissection and endoscopic mucosal resection: progress, techniques, and new directions
}

De Moura EGH, Monte Junior ES. Endoscopic submucosal dissection and endoscopic mucosal resection: progress, techniques, and new directions. Arq Gastroenterol. 2021;58(2):129-30.

Therapeutic endoscopy has been in practice since the $1950 \mathrm{~s}^{(1)}$. It is a useful tool in the treatment of many diseases of the gastrointestinal tract. In recent decades, this field has become the first option to diagnose and treat early-stage neoplastic lesions. Endoscopic resection has been shown to be an appropriate handling of patients with early gastrointestinal cancers with or not limited submucosal involvement and no additional risk factors ${ }^{(2)}$.

Endoscopic resection has been performed basically as endoscopic mucosal resection (EMR) and endoscopic submucosal dissection (ESD). Understanding the origin of the basic concepts and the development of techniques is necessary to realize the current status and assess future prospects. Deyhle et al. ${ }^{(3)}$ described the basics of EMR in 1973. At that time, knowledge, endoscopes, and post-operative care were rare. Thus, only in the 1980s, EMR became popular in the world ${ }^{(4)}$. When compared to EMR, ESD requires a greater technological apparatus, and due to a higher risk of bleeding and perforation, it was an unusual technique in the beginning; Only in the 1990s, ESD became globally popular, gaining notoriety motivated by the good results in Japan ${ }^{(5)}$.

Regarding definitions, EMR is a method that involves a variety of techniques, such as suction, lift, and underwater. It can be broadly divided into two groups: suction (suck-and-cut) and non-suction (lift-and-cut). The standard approach consisted of submucosal injection (SI) to make protrusion of the lesion and snaring the protruded area. The injection aims to separate mucosal and submucosal lesions from the muscularis layer. Many solutions have been described from saline to solutions with $50 \%$ dextrose. However, SI is not necessary to perform an EMR. Underwater endoscopic mucosal resection (UEMR) is a variation of the technique which does not require submucosal injection ${ }^{(6)}$.
In this issue of Archives of Gastroenterology, Coutinho et al. described UEMR for small rectal neuroendocrine tumors ${ }^{(7)}$. This retrospective study was performed in two Brazilian institutions between June 2015 and October 2018. Eleven patients diagnosed with gastrointestinal neuroendocrine tumors (NETs) smaller than $12 \mathrm{~mm}$ in diameter underwent UEMR. There were nine patients diagnosed with G1 rNET and two with G2. All rNETs were removed en bloc and no vascular or perineural invasion was detected. One lesion was restricted to the mucosa and the other ten infiltrated the submucosa. The main outcome assessed was safety and efficacy of using the UEMR technique for treating small rectal neuroendocrine tumors. The results of the paper are encouraging, since UEMR achieved a $100 \%$ en bloc resection rate and an $81 \% \mathrm{R} 0$ resection rate, with no complications, considering the 60 -month follow-up.

Endoscopic submucosal dissection represents a safe and effective alternative for treating early-stage neoplastic lesions. En bloc resections are feasible by this method and allows an accurate pathological anatomical examination, evaluating submucosal and vascular invasion. Concerning advances in ESD technique, the emergence of Narrow Band Imaging (NBI) should be mentioned. Chromoendoscopy - aimed to assess the margin of the lesion - is the first step to resection and NBI allows a safe and quick evaluation. This step is common in all variations of ESD, including the hybrid endoscopic submucosal dissection (HESD). This technique is performed with only partial submucosal dissection followed by EMR using snare resection of the lesion. Many variations were created in the last decades, and literature lacks strong evidence to select the best one ${ }^{(5,8)}$.

Also in this issue of Archives of Gastroenterology, Ribeiro et al. report a single-center retrospective study comparing endo-

\footnotetext{
*Faculdade de Medicina da Universidade de São Paulo, Hospital das Clínicas, Unidade de Endoscopia Gastrointestinal. São Paulo, SP, Brasil.
} 
scopic submucosal dissection with circumferential incision (ESD-C) versus tunneling method for treatment (ESD-T) of superficial esophageal cancer $^{(9)}$. The first technique is performed through an incision along the oral margins and next at the caudal margin of the lesion, resulting in a C-shaped incision. After that, an oral-anal submucosal dissection is performed. Finally, the remaining mucosa at the lateral side of the tumor is incised until the circumference of the lesion is completely open. ESD-T involves the creation of a submucosal tunnel. The first step is to perform an incision in the distal margin of the lesion, after a submucosal infection with a $0.4 \%$ sodium hyaluronate. The same procedure is subsequently executed in the proximal margin of the tumor. Submucosal dissection is performed in the cranial-caudal direction, building a tunnel. Sixty-five esophageal ESD procedures were enrolled in the study, 23 of which belonged to the ESD-T group and 42 to the ESD-C group. No statistical difference was noted between the two techniques, regarding en bloc resection rate, $\mathrm{R} 0$ resection rate and curative resection rate. The data supports the absence of preferable techniques among ESD-C and ESD-T, both being feasible.
Nowadays, with the advance of therapeutic endoscopy, the complexity of procedures has been increasing, demonstrating the limitations of flexible endoscopes. Thus, new directions have emerged. Robotic flexible endoscopy (RFE) is a new frontier of endoscopic submucosal dissection. One of the limitations regarding current endoscopes is the absence of articulated movements, which are necessary to perform complex dissections and remove huge lesions. Considering this limitation, robotic flexible endoscopy has brought more degrees of freedom to improve triangulation and traction for dissections ${ }^{(10)}$. In conclusion, we are living in an era of advances in therapeutic endoscopy. The evolution, the new paradigms, and the speedy advances in endoscopic resection are proof of this.

\section{Eduardo Guimarães Hourneaux DE MOURA*} and Epifanio Silvino do MONTE JUNIOR*

\section{Orcid}

Eduardo G. Hourneaux de Moura: 0000-0002-8023-3722.

Epifanio Silvino do Monte Junior: 0000-0001-7304-8222.

De Moura EGH, Monte Junior ES. Dissecção submucosa endoscópica e mucosectomia: progresso, técnicas e novos rumos. Arq Gastroenterol. 2021;58(2):129-30.

\section{REFERENCES}

1. Landin MD, Guerrón AD. Endoscopic Mucosal Resection and Endoscopic Submucosal Dissection. Surg Clin North Am. 2020;100:1069-78. DOI: 10.1016/j. suc.2020.07.004.

2. Pimentel-Nunes P, Dinis-Ribeiro M, Ponchon T, Repici A, Vieth M, Ceglie A, et al. Endoscopic submucosal dissection: European Society of Gastrointestinal Endoscopy (ESGE) Guideline. Endoscopy. 2015;47:829-54. DOI: 10.1055/s-0034-1392882.

3. Deyhle P, Jenny S, Fumagalli I. Endoscopic polypectomy in the proximal colon. A diagnostic, therapeutic (and preventive?) intervention. Dtsch Med Wochenschr. 1973;98:219-20. DOI: 10.1055/s-0028-1106782

4. Nishizawa T, Yahagi N. Endoscopic mucosal resection and endoscopic submucosal dissection. Curr Opin Gastroenterol. 2017;33:315-19. DOI: 10.1097/ MOG.0000000000000388

5. Tanaka S, Kashida H, Saito Y, Yahagi N, Yamano H, Saito S, et al. JGES guidelines for colorectal endoscopic submucosal dissection/endoscopic mucosal resection. Dig Endosc. 2015;27:417-34. DOI: 10.1111/den.12456.

6. Pimentel-Nunes P, Dinis-Ribeiro M, Ponchon T, Repici A, Vieth M, De Ceglie A, et al. Endoscopic submucosal dissection: European Society of Gastrointestina Endoscopy (ESGE) Guideline. Endoscopy. 2015;47:829-54. DOI: 10.1055/s-00341392882 .
7. Coutinho LMA, Lenz L, Kawaguti FS, Martins BC, Baba E, Gusmon C, Andrade G, Simas M, Safatle-Ribeiro A, Maluf-Filho F, Rodrigues R, Ribeiro Junior U. Underwater endoscopic mucosal resection for small rectal neuroendocrine tumors. Arq Gastroenterol. 2021;58(2):210-3. DOI: 10.1590/S0004-2803.202100000-37.

8. Li Q-L, Yao L-Q, Zhou P-H, Xu M-D, Chen S-Y, Zhong Y-S, et al. Submucosal tumors of the esophagogastric junction originating from the muscularis propria layer: a large study of endoscopic submucosal dissection (with video). Gastrointest Endosc. 2012;75:1153-8. DOI: 10.1016/j.gie.2012.01.037.

9. Ribeiro TML, Arantes V, Ramos JA, Draganov PV, Yang D, Guimarães RG. Endoscopic submucosal dissection with circumferential incision versus tunneling method for treatment of superficial esophageal cancer. Arq Gastroenterol. 2021;58(2):195-201. DOI: 10.1590/S0004-2803.202100000-35.

10. Visconti TAC, Otoch JP, Artifon ELA. Robotic endoscopy. A review of the literature. Acta Cir Bras. 2020;35:e202000206. DOI: 10.1590/s0102 865020200020000006 . 